\title{
Three Curriculum of Knowledge, Ability and Literacy Goals that Assist University Chinese Course out of the Woods
}

\author{
Wang Yanli, a \\ ${ }^{1}$ Primary Educational Dept., Wuhan City Vocational College, Wuhan, Hubei, PRC Postal Co \\ de: 430067 \\ awangyanli1967@126.com
}

Keywords: Knowledge, Ability and Literacy, Target, University Language Courses, Out of the Woods

\begin{abstract}
For the current status of marginalized university language teaching we have proposed a new course mode based on the National Education Thought Leader Shuren, integrating the three major functions of language play, and build knowledge - ability - literacy three-dimensional space-style curriculum, exploring university language integration and developing students' knowledge basic, practical ability and three-dimensional integrated humanities curriculum goals .
\end{abstract}

May 2013, The media continued to report in Wuhan for a week revealing marginalized university teaching language courses, teacher marginalized news, In September, Renmin University of China announced the change from the required courses for elective the university language course, it is a stone -excited Splash from university language courses to re-enter the audience attention. Followed by "Guangming Daily", "China Education” after another article discusses the university had severe language problems increasingly embarrassing . In fact, since the 1980s, Chinese language courses University Higher recovery, all these problems have been repeatedly exposed, so this has been nothing new. But the real news is that, in today's globalized deepening, strengthening language education has almost become a social consensus, on the one hand is a group consensus of society, on the one hand and university language courses in many universities, the media exposure the highest course one, but always with a negative image, “dilemma”, "awkward “, "edge "and appeared in the vision of society. So much attention by the community college language exactly how, why always in such an embarrassing predicament?

Engaged in language teaching as a full-time university teacher, I believe that the language of this embarrassing situation of university education and its current situation demands a serious discrepancy about the times as a course, university language has not discipline their position, there is no constant curriculum standards, There is no uniform syllabus, let alone advancing innovation and reform of teaching . To solve it embarrassing situation fundamentally, by discipline of, by policy support, will be the successor weakness. University language courses imminent fundamental task is thought to be based on the National Education Rucker tree round development of people, knowing and doing justice to the three-dimensional reconstruction of university language courses curriculum objectives .

First, the current status quo and problems of language education university :

The current university language education goals are the following view: First, the "tool"that emphasizes university language as their mother tongue language teaching tool to use as teaching material manifestations of this theory to practical writing, presentation skills, etc. are also included in the written style ; second is "literature ", says this theory is that literature is the highest form of native language, beautiful literature disseminated to influence students to play the role ; third is the "cultural topics,"said the theory that college students should be language play the role of cultural accumulation, cultural topics form the performance of materials, such as "Nine Chapters on Arithmetic "is also incorporated into the textbooks; fourth is "Human Subject"said Professor Qi Senhua this theory is representative of East China Normal University, stressed the university language enhance students' humanities ; five is "mother tongue education"that it is based on a theory of "globalization"as the background made by Native college Students survey by weakening the strong position with native speakers of English and Chinese Health issued the crisis, view 
national crisis, thus strengthening higher education in mother tongue education.

These views are simply grouped into two generally recognized university language education goals : Tools that humanities said.

These sorts of viewpoints into one of the words, there are pros and cons of co-existence issues, such as tools that emphasize the use of language as a tool, and "workplace communication", "lecture and eloquence "and how the course boundary points ; mother tongue education say how specific implementation, and how to distinguish primary and secondary language, will become a high four languages and so much more. The overall sum up, the current university language education exist : partial ugly point, the lack of integration ; levels is unknown, lack of orientation ; conceptual differences, lack of deepening ; research is weak, weak guidance ; single method, the lack of diverse ; migraine management weaker real, Tao has two classification problems. The root of these problems lies in armed with a speech, the lack of national Rucker Shuren, comprehensive development of educational thought in-depth understanding of the overall grasp.

Second, the current university language education and Rucker Shuren

2006, issued by the State Department of Higher Education to teach high [ 2006 ] No. 16, "a number of opinions on the overall improvement of teaching quality of higher vocational education,"said: "higher vocational institutions should adhere to people-centered education, moral education first, the Rucker as the fundamental task. ... train a group of highly qualified skilled talent . "spirit of the document is very clear, the Rucker as the fundamental task of vocational education.

Rucker Shuren is a very common word in the language education universities, one university language function is also recognized by everyone - students on the proper formation of the world, to enhance students' cultural literacy. Rucker Shuren refers to education for students ideological soul spiritual enlightenment world do ? We need to re-examine the next word .

From the literature we can see, at the earliest, "Rucker "and "tree people "are separate. "Lide "first out "tree people "after the "Lide "from "Zuo Zhuan": "There are too Rucker, followed by meritorious service, followed by a Liyan, though eventually becoming waste, what is called immortality ."Ancients believed that a person wants to achieve the highest level of life, we must first establish high moral interests, to achieve the lofty moral ideals ; secondly to pursue a successful career, make contributions ; finally to achieve theoretical and systematic thinking, wrote books, which many scholars of the three is the lifelong pursuit of the so-called ancient life "Three Immortality ."The ancients, "Rucker "placed in the "Three Immortality," the head of the "Leader "as "meritorious "and "Li Yan"premise and foundation of ancient Chinese society profoundly reflects the pursuit of morality and the importance of moral education. As can be seen, Rucker emphasized that the spiritual quality of education for students to develop the level of enlightenment .

"Tree people "thinking out of the first "pipe “: "Yinianzhiji, nurturing Tree Valley ; decade, plant trees ; lifelong ahead, plant a tree people ", meaning that the year is going to grow food ; species after the tree is going to be ten years ; and personnel training is for long-term plans . Today often say "ten years to grow a tree,"is derived from this . As can be seen, the tree is stressed education skills training for students' ability training .

Due to the high correlation of these two concepts, so in practice, people gradually merging them directly linked to the use of a word, as if Rucker is in the tree people . Especially our political, cultural and other public language courses, which takes Rucker as the only path to your own tree or simply call people.

Numerous facts have proven Rucker and tree people are two separate concepts, "Germany "can not naturally need "stand “, "people "can not self -taught and needs "tree ."Germany "stand “, and people may not be able to become a tree, the tree people, no morality, but also a long become diseased trees . These two concepts are complementary, "Rucker "is to "tree people ", and "tree people "first "Leader ."Leave "Lide "talk "tree people “, will deviate from the right direction, "tree"bad "person"; while leaving the "tree people "talk "Rucker "will become empty forms, "Li "bad "Germany ." 
Report of the party's 18 again reaffirmed education "Rucker tree people is the fundamental task ."This idea, both the deep roots of Chinese civilization, but also embodies the spirit of progress and development of the times, is a new educational philosophy in the new situation and the conditions put forward, with new content and rich theoretical scientific implication . The current university language education tools Shuren said the emphasis on language, culture, said the emphasis on text Rucker, will be biased and one-sided. You can put it bluntly, it is precisely because of this biased and one-sided, leading universities and the real impact of language extinction water, the media screamed Huan, hot club meetings on campus, but increasingly marginalized.

Third, based on Rucker Shuren, reconstructed language courses University System

University Language is not simply to teach students speaking and writing tools, nor is "Two "complement and Supplements, which has its own three functions : to impart knowledge of the language, develop core competencies, improve the quality of conservation, which both "missionary “, "tuition “- tree people, but also, "he argued,"“enlightenment "Rucker . Higher vocational colleges especially in just three or four years to complete the task of students professional skills, it is impossible to give basic courses more time and space. In the limited time and space, "dance in shackles "of university language, any inclination to achieve its single function, are the biggest waste of education and biased. Only maximize integration play its three functions, and build knowledge OK - curriculum system -defined three-dimensional space -like, to explore the development of culture -based curriculum integration of students' knowledge base, practical skills and training model three-dimensional integration of the humanities, not only to teach basic cultural knowledge to students, students 'pragmatic competence, but also to cultivate students' professional ethics, humanities, social skills and overall quality, reshape university language teaching philosophy, to achieve higher education both "Leader "and "tree people "the ultimate philosophy of education, limited hours of language lessons in the performance of the University to maximize, to eventually become increasingly marginalized native education to the proper height and position, the university language courses in the curriculum only play a structural role of marginalization back, the full realization of their educational practice role functionality.

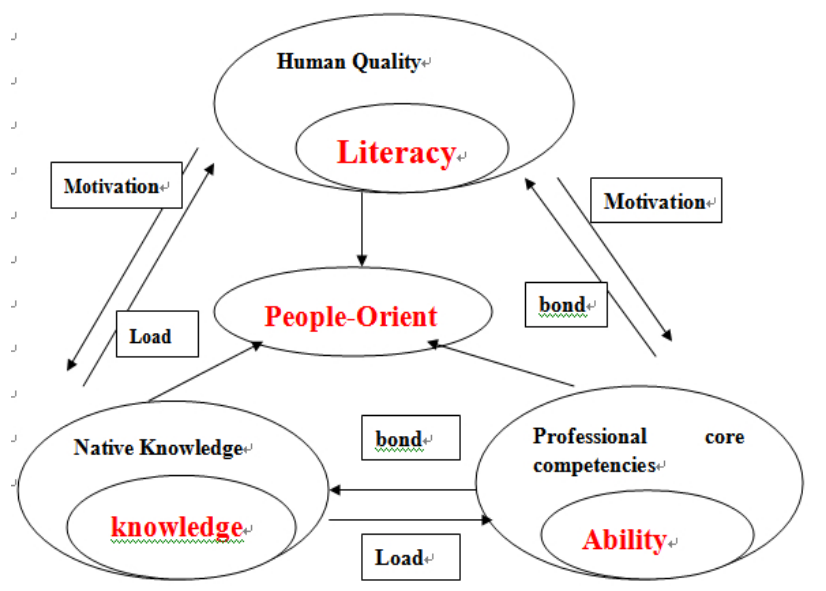

In this framework :

Native knowledge : knowledge (knowledge) is an objective property of things with contact reflected in the human brain, is the outcome of human knowledge . Categories are the basics of any capacity and quality of the carrier and tie, is student learning, teaching and fundamental starting point is to develop core competencies, shaping the quality of students preconditions, without the awareness of construction, students learning is empty, the contents of the teacher is Professor mirage .

Native knowledge involves not only explore issues papers, then repair logic text, but also knowledge in all aspects of life, society and nature. Knowledge of languages is a prerequisite for the formation of language proficiency and language literacy. Students master the knowledge and be able to apply this knowledge in life to writing literacy, reading, writing, oral communication, integrated learning. The persistence of knowledge into pragmatic ability to be used in the expression of life, thinking, will be communicative . Use it to spread the culture, the creation of 
human civilization, for my own life full development, to lay a solid foundation for lifelong learning .

Core competencies : professional core competence is achieved in people's life and work capacity in addition to the basic capabilities of professional positions necessary for success, it can make people show their confidence and success, and how to choose and apply depending on the circumstances .

In 1998 the Ministry of Labor and Social Security in the "revitalization of the national skills strategy "will be divided into professional core competencies : Communication skills, digital applications, understanding skills, teamwork skills, problem solving skills, self- learning ability, innovation and innovation capability, eight foreign language proficiency corresponding modules. "Opinions on the overall improvement of teaching quality of higher vocational education "(teach high [2006] No.16 ) clearly stated, "to strengthen the professional capacity of students," and stressed that "for the students to the characteristics of higher vocational colleges, students of social adaptability, education students to establish the concept of lifelong learning, improve learning ability, learn communication and teamwork, improve students' practical ability, creative ability, employability and entrepreneurship . "Since then, students of professional competence (professional capabilities and core competencies ) become a trend of vocational education.

Humanistic qualities: the quality of the humanities education in educational subjects who reflected the results, including language and text accomplishment, literary and artistic accomplishment, ethical and moral cultivation, cultivation of civility, political theory cultivation, history and philosophy of training and so on. Humanistic Education in its basic spirit, with emphasis on human sexuality education, perfect personality for the purpose, in order to focus on achieving and promoting the harmonious development of the individual physical and mental training objectives .

Humanistic Education is the latest cultural achievements of mankind through humanities education, teaching and nurturing educational environment of the theory of knowledge, so as within the personality, temperament, training, and gradually form a stable intrinsic quality and value orientation . Its core is to educate students to "learn to be “to promote students to think about life's purpose, significance, value and development of humanity, perfect personality, guiding students to form a certain outlook on life, morality, values, aesthetics, the pursuit of human landscaping, inspiring them make a real person, to be a wise man, be a cultivated person .

German educator Jaspers said: "Education is the human soul of education, rather than the accumulation of knowledge and understanding of reason .”In this sense, education is the foundation of humanistic education and the ultimate goal.

Three-dimensional framework : human life is life as a whole physical, spiritual, cultural and information. Contemplation of human life as a whole, and promote the overall development of people, education is one of the most important tasks. Today's students face the task of constructing the three worlds : one is the formation of the world's knowledge (knowledge ), the second is the social life of the world (ROW ), the third is the spiritual world (righteousness ). Around, "Rucker tree people "educational philosophy of "knowledge - OK - meaning" three-dimensional object, give students knowledge of the tension, with the ability to core skills to the vitality of the human spirit, which condensed into student life to build the world 's fresh live vitality.

This three-dimensional space is three-dimensional, steady, regardless of severity, regardless of length, jointly completed "Rucker tree people"educating people of the country.

Finally, I apply the famous educator Mr. Pan Maoyuan passage to summarize this ideal process, "humanities knowledge (knowledge ) must be translated into human spirit (righteousness ), and for the explicit behavior (lines ), in order to constitute a relatively stable quality construction (adult ). “

University of righteousness language to know the three-dimensional framework for curriculum objectives are fully in line with the overall development of the country Rucker Shuren educational thought, so it is scientific and rational, and fully meet its nature as humanities. Thus it is also practical, curriculum aims Gang, Zhang Gang lift and head clear scientific and practical university language course aims ultimately help out embarrassing . 


\section{References}

[1] Dan Tianqiang, The Language Should Have the Spirit of "Reform" [N] China Education Daily, May 24, 2013

[2] Important Issues Ailing Curriculum Reform : Focus on overall development of the people [J] Educational Research, 2007, (9 )

[3] Cao Xiang Seeing University Language Teaching Materials Preparation From the Culture Orientation [J] Liuzhou Vocational \& Technical College, 2012 (12 )

[4] Understanding and Practice Shi Yanhong Highly Skilled Personnel Training Mode [J] Chinese Adult Education, 2010 (13)

[5] Wang Jian-yong Career Planning and Implementation Capacity of the Perspective of Chinese Vocational Course [J] Chinese Adult Education, 2009 (9) 